\title{
. \\ Plant Health and Sound Vibration: Analyzing Implications of
the Microbiome in Grape Wine Leaves
}

Birgit Wassermann ${ }^{1}$, Lise Korsten ${ }^{2}$ and Gabriele Berg ${ }^{1, *}$

1 Institute of Environmental Biotechnology, Graz University of Technology, Petersgasse 12, 8010 Graz, Austria; birgit.wassermann@tugraz.at

2 Department of Plant and Soil Sciences, University of Pretoria, Pretoria 0002, South Africa; lise.korsten@up.ac.za

* Correspondence: gabriele.berg@tugraz.at; Tel.: +43-316-873-8310

Citation: Wassermann, B.; Korsten L.; Berg, G. Plant Health and Sound Vibration: Analyzing Implications of the Microbiome in Grape Wine Leaves. Pathogens 2021, 10, 63. https://doi.org/10.3390/pathogens 10010063

Received: 8 October 2020 Accepted: 8 January 2021 Published: 12 January 2021

Publisher's Note: MDPI stays neutral with regard to jurisdictional clai$\mathrm{ms}$ in published maps and institutional affiliations.

Copyright: (C) 2021 by the authors. Licensee MDPI, Basel, Switzerland. This article is an open access article distributed under the terms and conditions of the Creative Commons Attribution (CC BY) license (https:// creativecommons.org/licenses/by/ $4.0 /)$.

\begin{abstract}
Understanding the plant microbiome is a key for plant health and controlling pathogens Recent studies have shown that plants are responsive towards natural and synthetic sound vibration (SV) by perception and signal transduction, which resulted in resistance towards plant pathogens. However, whether or not native plant microbiomes respond to SV and the underlying mechanism thereof remains unknown. Within the present study we compared grapevine-associated microbiota that was perpetually exposed to classical music with a non-exposed control group from the same vineyard in Stellenbosch, South Africa. By analyzing the 16S rRNA gene and ITS fragment amplicon libraries we found differences between the core microbiome of SV-exposed leaves and the control group. For several of these different genera, e.g., Bacillus, Kocuria and Sphingomonas, a host-beneficial or pathogen-antagonistic effect has been well studied. Moreover, abundances of taxa identified as potential producers of volatile organic compounds that contribute to sensory characteristics of wines, e.g., Methylobacterium, Sphingomonas, Bacillus and Sporobolomyces roseus, were either increased or even unique within the core music-exposed phyllosphere population. Results show an as yet unexplored avenue for improved plant health and the terroir of wine, which are important for environmentally friendly horticulture and consumer appreciation. Although our findings explain one detail of the long-term positive experience to improve grapevine's resilience by this unusual but innovative technique, more mechanistic studies are necessary to understand the whole interplay.
\end{abstract}

Keywords: Vitis vinifera; grapevine; microbiota; phyllosphere; synthetic sound vibration; terroir; resilience

\section{Introduction}

Plants and their associated microbes have been interacting with each other for a long time, forming assemblages of species that is referred to as a holobiont $[1,2]$. The composition of the plant microbiota varied during plants' life cycle and is vertically transmitted [3]. Plant-associated microorganisms trigger important processes in plants, e.g., germination, circadian and annual cycles, fruit and seed formation and significantly contribute to plant health [4]. Interestingly, each healthy plant microbiome contains potential pathogenic microorganisms and their antagonistic counterparts, which together form a balanced functional network [5]. Antagonistic mechanisms, which convey this balance, are used for a long time to biologically control pathogens (reviewed [6,7]). The mode of action mediating antagonism includes (i) inhibition of microbial growth by diffusible antibiotics and volatile organic compounds (antibiosis), (ii) competition for colonization sites and nutrients, (iii) competition for minerals, (iv) degradation of pathogenicity factors of the pathogen such as toxins and (v) parasitism and lysis that involve production of extracellular cell wall-degrading enzymes such as chitinases and $\beta-1,3$-glucanase [8]. In addition, plantassociated microorganisms are able to directly activate the plant defense system by induced systemic resistance (ISR), which sometimes overlaps partly with that of pathogen-induced 
systemic acquired resistance (SAR); both ISR and SAR represent a state of enhanced basal persistence of the plant that depends on the signaling compounds jasmonic acid and salicylic acid [9].

Recent studies have shown that, in addition to plant-associated microorganisms, plants are also responsive towards natural and synthetic sound vibration (SV) by perception and signal transduction and activating ISR [10]. This resulted in resistance towards plant pathogens such as Botrytis cinerea [11], and improved plant health [12]. Moreover, novel data provide increasing evidence of a molecular mechanism for sound perception and transduction, improving germination, growth, development, crop yield and increased tolerance to drought stress [13-15]. Plants respond to the chewing sound of insect larvae, the buzz pollination of bees $[16,17]$, and bat-dependent plants evolved acoustic reflectors for the bat echolocation system to attract their pollination partners [18]. These observations confirm acoustic communication beyond kingdoms with beneficial implications for the plant. Even unicellular organisms are suggested to respond in growth, metabolism, antibiotic and stress tolerance, when subjected to SVs [19-21], but to date, no study investigating the effect on the entire microbiota. Our hypothesis was that SV targets not only pathogens, it shifts the whole microbiome into a balanced state, which mediated better health and plant traits.

To verify this hypothesis, we used grape (Vitis vinifera L.) as a model. The indigenous microbiome [22-26] and pathogens [27] are well studied. The grape-associated microbiota was found to be involved in plant health [28]; and, by their volatile organic compounds on the vitivinicultural terroir [29-34]. Currently, conventional and organic grape production depend on high amounts of pesticides, which have to be drastically reduced [35]. Physicostimulants like SVs, which have not been investigated on grapevine- or any other plantassociated microbiota, offers an environmentally friendly possibility to control pathogens. For the purpose of evaluating an effect of SVs in form of audible sound on native phyllosphere microbiota, we examined grapevine leaves (cultivar "Syrah") from the vineyard De Morgenzon in Stellenbosch, South Africa (https://demorgenzon.com/music/) that was continually exposed to classical, mainly baroque music for the duration of the whole growing season, and compared them to non-exposed leaves. This pilot study proposes an effect of SV in form of music on the phyllosphere microbiome of grapevines, potentially supporting plant resilience and intensifying the terroir of red wine.

\section{Results}

\subsection{The General Bacterial and Fungal Structure of the Grapevine Phyllosphere}

Quality filtering using the DADA2 algorithm, removal of chimeric sequences and additional removal of mitochondrial and chloroplast sequences from the 16S rRNA gene fragments, yielded a 16S rRNA dataset containing 108,450 paired reads, assigned to 844 features and an internal transcribed spacer (ITS) region dataset consisting of 740,348 paired reads, assigned to 337 fungal features. Datasets were rarefied to 1205 bacterial and 30,298 fungal sequences, according to the sample with the lowest number of reads. Both the "Music" and the "Control" samples were dominated by Proteobacteria (61\% and $45 \%$, respectively), followed by Firmicutes (19\% and 32\%, respectively) and Actinobacteria (16\% and $19 \%$, respectively). Among dominating bacterial classes, "Music" samples were composed of Gammaproteobacteria (51\%), Actinobacteria (14\%), Bacilli (14\%) and Alphaproteobacteria (9\%). Similarly, "Control" samples contained the same classes with abundances of $36 \%, 17 \%, 26 \%$ and $8 \%$, respectively. The fungal composition was found to be less consistent between the two groups. Here, "Control" samples were composed of 94\% Ascomycota and 6\% Basidiomycota, with the dominating classes Dothideomycetes $(93 \%)$ and Tremellomycetes (5\%). Exposure to music resulted in decreased abundance of Ascomycota (77\%) and an increase in Basidiomycota abundance (22\%); among them, Dothideomycetes and Tremellomycetes dominated again with $76 \%$ and $19 \%$, respectively.

In order to evaluate differences of microbial diversity within SV-exposed and nonexposed grapevine leaves, alpha and beta diversity analyses were observed for the whole 
dataset. We found no statistically significant difference in alpha diversity for the bacterial and fungal community; however, for both groups Shannon $\mathrm{H}^{\prime}$ index was higher in classical music-exposed leaves (Figure 1A,B). Beta diversity analyses, based on Bray Curtis dissimilarity matrix and assessed via pairwise analysis of similarity (ANOSIM), also revealed no significant differences for bacteria (Figure 1C) and fungi (Figure 1D).
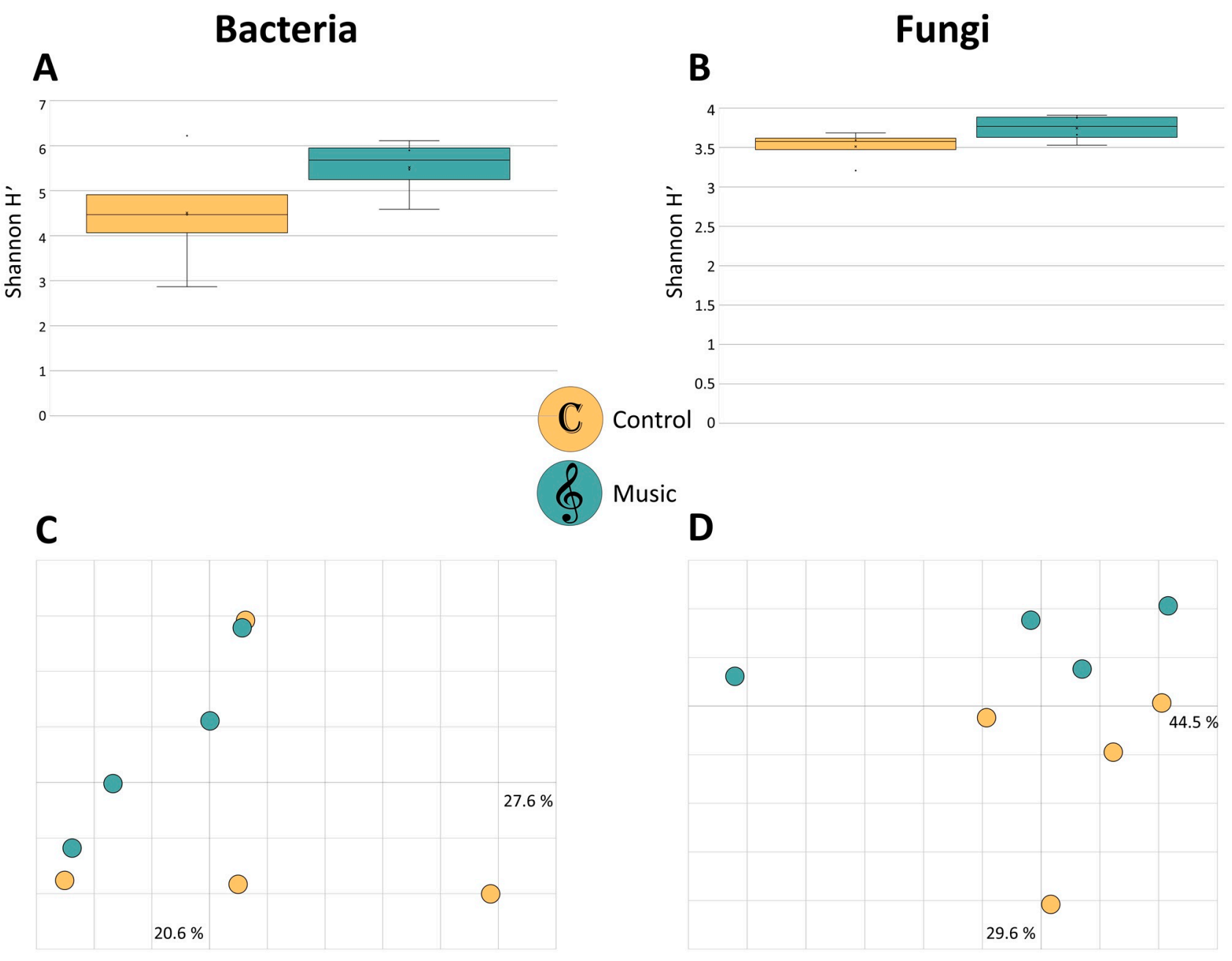

Figure 1. Alpha and beta diversity comparisons of grapevine leaf-associated bacterial and fungal communities. "Control" and "Music" samples are depicted in yellow and blue, respectively, as indicated by the legend in the figure center. Boxand-whiskers-plots represent bacterial (A) and fungal (B) alpha diversity, based on Shannon $\mathrm{H}^{\prime}$ index. Color-coded two dimensional Bray Curtis Principle Coordinates Analysis (PCoA) plots visualize community clustering of bacterial (C) and fungal (D) composition. Differences in alpha and beta diversity were not significant between the two groups, according to the Kruskal-Wallis test and analysis of similarity (ANOSIM) $(p<0.05)$, respectively.

\subsection{SV-Induced Differences in Phyllosphere Core Microbiomes Comprises Indicator Taxa for Resilience and Terroir}

In order to evaluate taxonomic composition changes induced by classical music, differential abundance based on the DESeq2 algorithm was tested on the entire feature table, resulting in no significant differences for taxa related to "Music" or "Control". Thus, core microbiota were defined for "Music" and "Control" groups using features that were present in $75 \%$ of the replicates of the respective group. Core microbiota were assigned to 12 bacterial and 39 fungal taxa at species level, serving as a matrix for network analyses (Figure 2). In total, 26 fungal and 3 bacterial species were shared by "Music" and "Control" groups; their total abundance within the respective group is indicated via pie charts in the 
network. Fungal microbiota were present in both "Control" (four) and "Music" (six) core networks. In contrast, core network bacteria (nine) were unique to classical music-exposed leaves. Accordingly, fungal and bacterial communities exposed to classical music exhibited a higher degree of homogeneity compared to "Control" leaves.

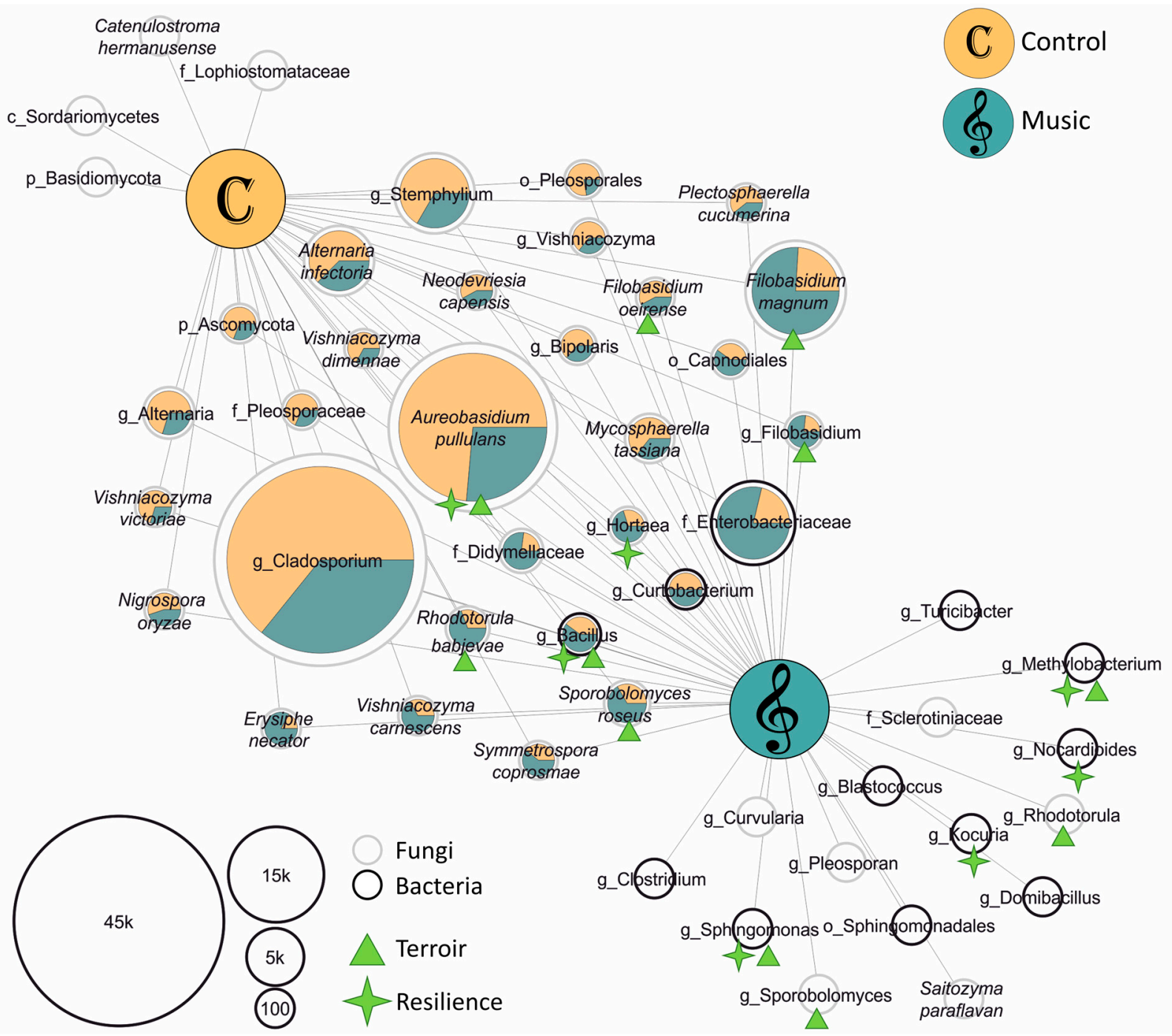

Figure 2. Shared and specific microbial taxa in sound vibration (SV)-exposed and control grapevine leaves. Only bacterial and fungal taxa (at species level) detected in at least $75 \%$ of the sample replicates were included in the network analysis. Node size corresponds to absolute abundance in the dataset and node outlines indicate bacteria (black) and fungi (grey) as indicated in the legend on the lower left. Pie charts of shared nodes indicate observed abundance within the two groups, where color of shared nodes is related to "Control" leaves (yellow) and "Music" leaves (blue). Green symbols attached to nodes point to the microbiota's potential for supporting host resilience (asterisks) and/or contributing to the terroir (triangle).

Next, we were interested in the potential impacts of the detected microbiota on plant health or the terroir. For that purpose, phyllosphere core taxa were subjected to literature research, revealing such functions for a total of 14 different taxa (indicated via green asterisks and triangles in Figure 2). Among them, only two (Aureobasidium pullans and Filobasidium oeirense) were more abundant in "Control" than in "Music" samples; however, both microorganisms were core members of the "Music" phyllosphere. The remaining 12 bacteria and fungi were either more abundant, or even unique within the core of SV-exposed leaves. Referring to current literature, grapevine-associated bacteria 
Kocuria and Nocardioides and the fungus Hortaea possess antagonistic properties towards necrotrophic Botrytis cinerea [36-38]. Methylobacterium and Sphingomonas strains counteract abundances of Candidatus phytoplasma, the causal agent of grapevine yellows [39], and several strains from the genus Bacillus are promising protective agents during heat and drought stress [22,40,41]. Regarding preferable impacts of microbiota on wine characteristics, abundances of Methylobacterium, Sphingomonas and Bacillus are positively correlated with typical sensory metabolites in finished wines [42]. Sporobolomyces roseus and A. pullans were identified to produce a broad spectrum of volatile organic compounds (VOCs) that are typical for wine terroir [29]; the same taxa, and the yeast genera Sporobolomyces, Rhodotorula and Filobasidium, are important participants of alcohol fermentation and the formation of the typical aromatic properties of wine [43-45].

\section{Discussion}

The present pilot study is the first describing potential impact of SVs in the form of music on the native plant microbiota. Our results suggest that perpetual exposure to music modulates the grapevine phyllosphere microbiota, demonstrating either increased abundance of specific bacteria and fungi, and under certain conditions, distinct taxa previously characterized for exhibiting beneficial characteristics in host resilience and/or wine terroir. This verified our hypothesis that SV induce a microbiome shift into a balanced state, which mediated better health and plant traits.

Among the latter, "Music"-associated taxa can be subdivided into the following groups: (i) their abundance correlates positively with the chemical composition and metabolite abundance of finished wines [42]; (ii) they have been identified to produce VOCs that are typical flavor compounds of red wine [29], and (iii) predominantly yeasts, that play important roles during alcohol fermentation, contributing significantly to quality and aromatic profiles of the product [43]. It has to be mentioned that (ii) and (iii) are not mutually exclusive. In fact, the production of wine is a complex process that includes the impact of bacterial and fungal consortia on wine chemistry [42].

Here, we must also point out the limitations of this pilot study. Despite our effort, an entirely randomized sampling was not practical due to the given circumstances in the vineyard; in particular, the positions of the speakers. Thus, an effect of soil-related variability between sampling points cannot be excluded. Integrating a starting situation without music and a subsequent examination of manipulating factors would furthermore allow a more comprehensive analysis. In addition, our observations must be confirmed for other Vitis cultivars and vineyards and in order to draw any conclusion on the impact of SVs on the taste of finished wines, the berry microbiota must be analyzed as well.

Nevertheless, $t$ studies of sound waves on plants $[10,11]$, plant pathogens $[10,12]$ and the total grapevine-associated phyllosphere microbiome uncovered in this study, showed that music potentially boosts plant health and resilience by activating a plant's immune system, prompting a corresponding microbiome shift. Furthermore, just as reinoculated grapevine-endophytic fungi have the potential to be applied as a fine-tuning regulator for wine grapes [46], we suggest music to be considered as a non-invasive agricultural management parameter that can augment the grapevine microbiome towards a favorable composition, thereby impacting the quality and characteristics of wine. However, the development of any microbiological application utilizing sound stimulation requires sufficient and in-depth fundamental research on the holobiont's response to music. Detailed metabolomic analyses of the effect of specific SVs (hertz) and loudness (decibel) on the plant's immune system are required to understand the underlying mechanisms. Nevertheless, this study suggests that SV in the form of music might impact the grapevine microbiome with yet unexplored potential for plant health and the terroir that is important for sustainable and environmentally friendly horticulture. 


\section{Materials and Methods}

\subsection{Experimental Design and Sample Processing}

For the microbiome analyses, leaves of Vitis vinifera L. (cultivar "Syrah") were collected in February 2019 from the vineyard De Morgenzon in Stellenbosch, South Africa. A subarea of the vineyard was planted in 2004 and equipped with loudspeakers, continually playing classical music (Baroque, and early Classic of selected composers) for $24 \mathrm{~h}$ daily and seven days a week over the whole growing season. More information about the background you can find here: https://demorgenzon.com/music/. According to the vineyard's owners, after seven years of experience, "phenolic ripeness with lower sugar levels which results in wines with all the ripeness, fruit, and acidity one would want, but with slightly lower alcohol levels" were observed. For SV-exposed grapevine leaf samples (henceforth referred to as "Music") four different Vitis plants, growing in close proximity to four different loudspeakers were selected. Each of the four replicates consisted of five randomly selected leaves, carefully preventing an effect of light exposure. Similarly, negative control samples ("Control") were taken from the same orchard, and at the same day and time, but most distantly located to the speakers, where no music was audible. Aerial photograph from Google maps [47] indicating sampling points for "Music" and "Control" replicates are provided in the Supplementary Materials (Figure S1). No visible difference between leaves of "Music" and "Control" plot was observed during the sampling. Leaf samples were placed on ice immediately until processing under sterile conditions in the laboratory. For each replicate a total leaf area of $780 \mathrm{~cm}^{2}$ was analyzed by placing leaves on a cardboard stencil covered with sterile freezer bags and the microbial community was acquired from leaves by a series of washing and sonication steps according to the method described by Ortega et al. [48]. The total microbial suspension of each replicate was centrifuged at $6170 \times g$ for $20 \mathrm{~min}$. The supernatant was removed and the moist pellet was transferred to a $2 \mathrm{~mL}$ Eppendorf tube and centrifuged again at $16,000 \times g$ for $20 \mathrm{~min}$. Pellets were stored at $-70{ }^{\circ} \mathrm{C}$ until further DNA extraction.

\subsection{Library Generation and Illumina MiSeq Sequencing of $16 S$ rRNA Gene and ITS Regions}

Total community DNA was extracted using the FastDNA Spin Kit for Soil (MP Biomedicals, Solon, OH, USA) according to the manufacturer's instructions using a FastPrep Instrument (MP Biomedicals, Illkirch, France) for $30 \mathrm{~s}$ at $5 \mathrm{~ms}^{-1}$. The following primer combinations were used for Illumina amplicon sequencing: 515f-806r [49] and ITS1f-ITS2r [50] to amplify the $16 \mathrm{~S}$ rRNA gene fragments and the ITS region, respectively, with three technical replicates per sample. Amplification of host plastid and mitochondrial 16S DNA was blocked by adding peptide nucleic acid (PNA) [51] clamps to the PCR mix. PCR for $16 S$ rRNA gene amplification was performed in a total volume of $30 \mu \mathrm{L}$ containing $5 \times$ Taq\&Go (MP Biomedicals, Illkirch, France), $1.5 \mu \mathrm{M}$ PNA mix, $0.25 \mathrm{mM}$ of each primer, PCR-grade water and $1 \mu \mathrm{L}$ template DNA. 16S rRNA gene fragment PCR was conducted using the following cycling conditions: $95{ }^{\circ} \mathrm{C}$ for $5 \mathrm{~min}, 30$ cycles of $96{ }^{\circ} \mathrm{C}$ for $1 \mathrm{~min}, 78{ }^{\circ} \mathrm{C}$ for $5 \mathrm{~s}$, $54{ }^{\circ} \mathrm{C}$ for $1 \mathrm{~min}, 74{ }^{\circ} \mathrm{C}$ for $60 \mathrm{~s}$ and a final elongation at $74{ }^{\circ} \mathrm{C}$ for $10 \mathrm{~min}$. PCR mix for ITS region amplification contained $5 \times$ Taq\&Go, $25 \mathrm{mM} \mathrm{MgCl}_{2}, 10 \mu \mathrm{M}$ of each primer, PCR-grade water and $1 \mu \mathrm{L}$ template DNA, in a total of $20 \mu \mathrm{L}$. ITS region amplification was performed under the following cycling conditions: $95{ }^{\circ} \mathrm{C}$ for $5 \mathrm{~min}, 30$ cycles of $94{ }^{\circ} \mathrm{C}$ for $30 \mathrm{~s}, 58{ }^{\circ} \mathrm{C}$ for $35 \mathrm{~s}, 72{ }^{\circ} \mathrm{C}$ for $40 \mathrm{~s}$ and final elongation at $72{ }^{\circ} \mathrm{C}$ for $10 \mathrm{~min}$. A nested PCR step was carried out to add barcoded primers. The three technical replicates were combined and purified using Wizard SV Gel and PCR Clean-Up System (Promega, Madison, WI, USA). Samples were combined in equimolar concentration according to Nanodrop 2000 (Thermo Scientific, Wilmington, DE, USA) measurements, and then sequenced using Illumina MiSeq v2 (250 bp paired-end) amplicon sequencing.

\subsection{Illumina MiSeq Data Processing and Statistics}

Forward and reverse reads were joined in QIIME 1.9.1 and imported into QIIME 2 2019.1 where all downstream analyses were performed. Using the DADA2 algorithm, 
sequences were quality filtered, chimeric sequences were discarded and a feature table was constructed, containing sequence variants and representative sequences. Features were classified using a Naïve-Bayes feature classifier trained on Silva132 (16S rRNA gene) [52] and UNITE v7.2 (ITS) [53] databases. Mitochondria and chloroplast reads were discarded from $16 \mathrm{~S}$ dataset. Core diversity script of QIIME 2 was applied to investigate alpha and beta diversity by rarefying feature tables to the lowest value of reads present in one sample. In order to evaluate taxonomic differences, core microbiomes were constructed, containing features present in $75 \%$ of the sample replicates. The OTU network was constructed on core bacterial and fungal species using Cytoscape version 3.5. [54]. Statistical analyses were performed in QIIME 1.9.1 and QIIME2 2019.1 using the Kruskal-Wallis test and analysis of similarity (ANOSIM) to test for significant differences in alpha (Shannon diversity) and beta (Bray Curtis dissimilarities) diversity, respectively.

Supplementary Materials: The following are available online at https:/ / www.mdpi.com/2076-081 7/10/1/63/s1, Figure S1: Google maps images of sampling location.

Author Contributions: B.W. processed samples, analyzed data and wrote the manuscript, B.W., G.B. and L.K. designed the study, discussed results and wrote the manuscript. All authors have read and agreed to the published version of the manuscript.

Funding: This study was funded by the Austrian Federal Ministry of Education, Science and Research (BMBWF) within the framework of the "Scientific and Technological Cooperation" (WTZ) program (Grant No. ZA 01/2019). Open Access Funding by the Graz University of Technology.

Institutional Review Board Statement: Not applicable.

Informed Consent Statement: Not applicable.

Data Availability Statement: The raw sequence files supporting the findings of this article are available from the European Nucleotide Archive (ENA) at study Accession Number PRJEB37982.

Acknowledgments: We gratefully acknowledge the vineyard De Morgenzon in Stellenbosch, South Africa for enabling this study by providing grapevine leaf samples and Jarishma Gokul (Pretoria) for her critical review of the manuscript.

Conflicts of Interest: The authors declare that the research was conducted in the absence of any commercial or financial relationships that could be construed as a potential conflict of interest.

\section{References}

1. Vandenkoornhuyse, P.; Quaiser, A.; Duhamel, M.; Le Van, A.; Dufresne, A. The importance of the microbiome of the plant holobiont. New Phytol. 2015, 206, 1196-1206. [CrossRef] [PubMed]

2. Cordovez, V.; Dini-Andreote, F.; Carrión, V.J.; Raaijmakers, J.M. Ecology and Evolution of Plant Microbiomes. Annu. Rev. Microbiol. 2019, 73, 69-88. [CrossRef] [PubMed]

3. Berg, G.; Raaijmakers, J.M. Saving seed microbiomes. ISME J. 2018, 12, 1167-1170. [CrossRef] [PubMed]

4. Schlaeppi, K.; Bulgarelli, D. The Plant Microbiome at Work. Mol. Plant Microb. Interact. 2015, 28, 212-217. [CrossRef] [PubMed]

5. Berg, G.; Köberl, M.; Rybakova, D.; Müller, H.; Grosch, R.; Smalla, K. Plant microbial diversity is suggested as the key to future biocontrol and health trends. FEMS Microbiol. Ecol. 2017, 93. [CrossRef] [PubMed]

6. Whipps, J.M. Microbial interactions and biocontrol in the rhizosphere. J. Exp. Bot. 2001, 52, 487-511. [CrossRef] [PubMed]

7. Haas, D.; Défago, G. Biological control of soil-borne pathogens by fluorescent pseudomonads. Nat. Rev. Microbiol. 2005, 3, 307-319. [CrossRef]

8. Berg, G. Plant-microbe interactions promoting plant growth and health: Perspectives for controlled use of microorganisms in agriculture. Appl. Microbiol. Biotechnol. 2009, 84, 11-18. [CrossRef]

9. Van Loon, L.C. Plant responses to plant growth-promoting rhizobacteria. In New Perspectives and Approaches in Plant. GrowthPromoting Rhizobacteria Research; Springer: Berlin/Heidelberg, Germany, 2007; pp. 243-254.

10. Kim, S.K.; Jeong, M.J.; Ryu, C.M. How do we know that plants listen: Advancements and limitations of transcriptomic profiling for the identification of sound-specific biomarkers in tomato. Plant Signal. Behav. 2018, 13, e1547576. [CrossRef]

11. Choi, B.; Ghosh, R.; Gururani, M.A.; Shanmugam, G.; Jeon, J.; Kim, J.; Park, S.-C.; Jeong, M.-J.; Han, K.-H.; Bae, D.-W.; et al. Positive regulatory role of sound vibration treatment in Arabidopsis thaliana against Botrytis cinerea infection. Sci. Rep. 2017, 7, 1-14. [CrossRef]

12. Jung, J.; Kim, S.K.; Kim, J.Y.; Jeong, M.J.; Ryu, C.M. Beyond Chemical Triggers: Evidence for Sound-Evoked Physiological Reactions in Plants. Front. Plant Sci. 2018, 9, 25. [CrossRef] [PubMed] 
13. Mishra, R.C.; Ghosh, R.; Bae, H. Plant acoustics: In the search of a sound mechanism for sound signaling in plants. J. Exp. Bot. 2016, 67, 4483-4494. [CrossRef] [PubMed]

14. Vicient, C.M. The effect of frequency-specific sound signals on the germination of maize seeds. BMC Res. Notes 2017, 10, 1-5. [CrossRef]

15. López-Ribera, I.; Vicient, C.M. Drought tolerance induced by sound in Arabidopsis plants. Plant Signal. Behav. 2017, 12. [CrossRef]

16. Appel, H.M.; Cocroft, R.B. Plants respond to leaf vibrations caused by insect herbivore chewing. Oecologia 2014, 175, 1257-1266. [CrossRef]

17. De Luca, P.A.; Vallejo-Marin, M. What's the 'buzz' about? The ecology and evolutionary significance of buzz-pollination. Curr. Opin. Plant Biol. 2013, 16, 429-435. [CrossRef]

18. Schöner, M.G.; Schöner, C.R.; Simon, R.; Grafe, T.U.; Puechmaille, S.J.; Ji, L.L.; Kerth, G. Bats are acoustically attracted to mutualistic carnivorous plants. Curr. Biol. 2015, 25, 1911-1916. [CrossRef] [PubMed]

19. Gu, S.; Zhang, Y.; Wu, Y. Effects of sound exposure on the growth and intracellular macromolecular synthesis of E. coli k-12. PeerJ 2016, 4, e1920. [CrossRef]

20. Sarvaiya, N.; Kothari, V. Effect of audible sound in form of music on microbial growth and production of certain important metabolites. Microbiology 2015, 84, 227-235. [CrossRef]

21. Sarvaija, N.; Kothari, V. Audible Sound in Form of Music Can Influence Microbial Growth; Metabolism and Antibiotic Susceptibility. J. Appl. Biotechnol. Bioeng. 2017, 2,1-9. [CrossRef]

22. Salomon, M.V.; Bottini, R.; de Souza Filho, G.A.; Cohen, A.C.; Moreno, D.; Gil, M.; Piccoli, P. Bacteria isolated from roots and rhizosphere of Vitis vinifera retard water losses; induce abscisic acid accumulation and synthesis of defense-related terpenes in in vitro cultured grapevine. Physiol. Plant. 2014, 151, 359-374. [CrossRef] [PubMed]

23. Ma, Y.; Jiao, J.; Fan, X.; Sun, H.; Zhang, Y.; Jiang, J.; Liu, C. Endophytic bacterium Pseudomonas fluorescens RG11 may transform tryptophan to melatonin and promote endogenous melatonin levels in the roots of four grape cultivars. Front. Plant Sci. 2017, 7, 2068. [CrossRef]

24. Abdelfattah, A.; Sanzani, S.M.; Wisniewski, M.; Berg, G.; Cacciola, S.O.; Schena, L. Revealing Cues for Fungal Interplay in the Plant-Air Interface in Vineyards. Front. Plant Sci. 2019, 10, 922. [CrossRef] [PubMed]

25. Trotel-Aziz, P.; Abou-Mansour, E.; Courteaux, B.; Rabenoelina, F.; Clément, C.; Fontaine, F.; Alziz, A. Bacillus subtilis PTA-271 counteracts Botryosphaeria dieback in grapevine; triggering immune responses and detoxification of fungal phytotoxins. Front. Plant Sci. 2019, 10, 25. [CrossRef] [PubMed]

26. Pacifico, D.; Squartini, A.; Crucitti, D.; Barizza, E.; Schiavo, F.L.; Muresu, R.; Carimi, F.; Zottini, M. The Role of the Endophytic Microbiome in the Grapevine Response to Environmental Triggers. Front. Plant Sci. 2019, 10, 1256. [CrossRef] [PubMed]

27. Rathnayake, R.M.S.P.; Savocchia, S.; Schmidtke, L.M.; Steel, C.C. Characterisation of Aureobasidium pullulans isolates from Vitis vinifera and potential biocontrol activity for the management of bitter rot of grapes. Eur. J. Plant Pathol. 2018, 151, 593-611. [CrossRef]

28. Schmid, F.; Moser, G.; Müller, H.; Berg, G. Functional and Structural Microbial Diversity in Organic and Conventional Viticulture: Organic Farming Benefits Natural Biocontrol Agents. Appl. Environ. Microbiol. 2011, 77, 2188-2191. [CrossRef]

29. Verginer, M.; Leitner, E.; Berg, G. Production of volatile metabolites by grape-associated microorganisms. J. Agric. Food Chem. 2010, 58, 8344-8350. [CrossRef]

30. Bokulich, N.A.; Joseph, C.M.L.; Allen, G.; Benson, A.K.; Mills, D.A. Next-generation sequencing reveals significant bacterial diversity of botrytized wine. PLoS ONE 2012, 7, e36357. [CrossRef]

31. Liu, Y.; Rousseaux, S.; Tourdot-Maréchal, R.; Sadoudi, M.; Gougeon, R.; Schmitt-Kopplin, P.; Alexandre, H. Wine microbiome: A dynamic world of microbial interactions. Crit. Rev. Food Sci. Nutr. 2017, 57, 856-873. [CrossRef]

32. Knight, S.; Klaere, S.; Fedrizzi, B.; Goddard, M.R. Regional microbial signatures positively correlate with differential wine phenotypes: Evidence for a microbial aspect to terroir. Sci. Rep. 2015, 5, 1-10. [CrossRef] [PubMed]

33. Vitulo, N.; Lemos, W.J.F.; Calgaro, M.; Confalone, M.; Felis, G.E.; Zapparoli, G.; Nardi, T. Bark and grape microbiome of Vitis vinifera: Influence of geographic patterns and agronomic management on bacterial diversity. Front. Microbiol. 2019, $10,3203$. [CrossRef]

34. Gilbert, J.A.; van der Lelie, D.; Zarraonaindia, I. Microbial terroir for wine grapes. Proc. Natl. Acad. Sci. USA 2014, 111, 5-6. [CrossRef]

35. Damalas, C.; Koutroubas, S. Farmers' Exposure to Pesticides: Toxicity Types and Ways of Prevention. Toxics 2016, 4, 1. [CrossRef]

36. Salomon, M.V.; Purpora, R.; Bottini, R.; Piccoli, P. Rhizosphere associated bacteria trigger accumulation of terpenes in leaves of Vitis vinifera L. cv. Malbec that protect cells against reactive oxygen species. Plant Physiol. Biochem. 2016, 106, 295-304. [CrossRef] [PubMed]

37. Andreolli, M.; Lampis, S.; Zapparoli, G.; Angelini, E.; Vallini, G. Diversity of bacterial endophytes in 3 and 15 year-old grapevines of Vitis vinifera cv. Corvina and their potential for plant growth promotion and phytopathogen control. Microbiol. Res. 2016, 183, 42-52. [CrossRef] [PubMed]

38. Núñez-Trujillo, G.; Cabrera, R.; Burgos-Reyes, R.L.; Silva, E.D.; Giménez, C.; Cosoveanu, A.; Brito, N. Endophytic fungi from Vitis vinifera L. isolated in Canary Islands and Azores as potential biocontrol agents of Botrytis cinerea Pers.: Fr. J. Hortic For. Biotechnol. 2012, 16, 1-6. 
39. Bulgari, D.; Casati, P.; Quaglino, F.; Bianco, P.A. Endophytic bacterial community of grapevine leaves influenced by sampling date and phytoplasma infection process. BMC Microbiol. 2014, 14, 198. [CrossRef]

40. Torres, N.; Goicoechea, N.; Zamarreño, A.M.; Antolin, M.C. Mycorrhizal symbiosis affects ABA metabolism during berry ripening in Vitis vinifera L. cv. Tempranillo grown under climate change scenarios. Plant Sci. 2018, 274, 383-393. [CrossRef]

41. Jiao, J.; Ma, Y.; Chen, S.; Liu, C.; Song, Y.; Qin, Y.; Yuan, C.; Liu, Y. Melatonin-producing endophytic bacteria from grapevine roots promote the abiotic stress-induced production of endogenous melatonin in their hosts. Front. Plant Sci. 2016, 7, 1387. [CrossRef]

42. Bokulich, N.A.; Collins, T.S.; Masarweh, C.; Allen, G.; Heymann, H.; Ebeler, S.E.; Mills, D.A. Associations among Wine Grape Microbiome; Metabolome; and Fermentation Behavior Suggest Microbial Contribution to Regional Wine Characteristics. MBio 2016, 7, 1-12. [CrossRef] [PubMed]

43. Prakitchaiwattana, C.J.; Fleet, G.H.; Heard, G.M. Application and evaluation of denaturing gradient gel electrophoresis to analyse the yeast ecology of wine grapes. FEMS Yeast Res. 2004, 4, 865-877. [CrossRef] [PubMed]

44. Fleet, G.H. Yeast interactions and wine flavour. Int. J. Food Microbiol. 2003, 86, 11-22. [CrossRef]

45. Pretorius, I.S. Tailoring wine yeast for the new millennium: Novel approaches to the ancient art of winemaking. Yeast 2000, 16, 675-729. [CrossRef]

46. Yang, M.Z.; Ma, M.D.; Yuan, M.Q.; Huang, Z.Y.; Yang, W.X.; Zhang, H.B.; Huang, L.H.; Ren, A.Y.; Shan, H. Fungal Endophytes as a Metabolic Fine-Tuning Regulator for Wine Grape. PLoS ONE 2016, 11, e0163186. [CrossRef]

47. DeMorgenzon, S. Google Maps. AfriGIS. 2020. Available online: https:/ / www.google.at/maps (accessed on 13 November 2020).

48. Ortega, R.A.; Mahnert, A.; Berg, C.; Müller, H.; Berg, G. The plant is crucial: Specific composition and function of the phyllosphere microbiome of indoor ornamentals. FEMS Microbiol. Ecol. 2016, 92, 173. [CrossRef]

49. Caporaso, J.G.; Kuczynski, J.; Stombaugh, J.; Bittinger, K.; Bushman, F.D.; Costello, E.K.; Fierer, N.; Peña, A.G.; Goodrich, J.K.; Gordon, J.I.; et al. QIIME allows analysis of high-throughput community sequencing data. Nat. Methods 2010, 7, 335-336. [CrossRef]

50. White, T.J.; Bruns, T.; Lee, S.; Taylor, J.W. Amplification and direct sequencing of fungal ribosomal RNA genes for phylogenetics. PCR Protocols: A Guide to Methods and Applications. Acad. Press. 1990, 64, 315-322.

51. Lundberg, D.S.; Yourstone, S.; Mieczkowski, P.; Jones, C.D.; Dangl, J.L. Practical innovations for high-throughput amplicon sequencing. Nat. Methods 2013, 10, 999-1002. [CrossRef]

52. Quast, C.; Pruesse, E.; Yilmaz, P.; Gerken, J.; Schweer, T.; Yarza, P.; Peplies, J.; Glöckner, F.O. The SILVA ribosomal RNA gene database project: Improved data processing and web-based tools. Nucleic Acids Res. 2013, 41, D590-D596. [CrossRef]

53. Kõljalg, U.; Nilsson, R.H.; Abarenkov, K.; Tedersoo, L.; Taylor, A.F.S.; Bahram, M.; Bates, S.T.; Bruns, T.D.; Bengtsson-Palme, J.; Callaghan, T.M.; et al. Towards a unified paradigm for sequence-based identification of fungi. Mol. Ecol. 2013, 22, 5271-5277. [CrossRef] [PubMed]

54. Shannon, P. Cytoscape: A Software Environment for Integrated Models of Biomolecular Interaction Networks. Genome Res. 2003, 13, 2498-2504. [CrossRef] [PubMed] 